This item was submitted to Loughborough's Research Repository by the author.

Items in Figshare are protected by copyright, with all rights reserved, unless otherwise indicated.

\title{
Performance of an acoustic emission monitoring system to detect subsurface ground movement at Flat Cliffs, North Yorkshire, UK
}

\section{PLEASE CITE THE PUBLISHED VERSION}

http://dx.doi.org/10.1007/978-3-319-09057-3

\section{PUBLISHER}

(C) Springer

VERSION

AM (Accepted Manuscript)

\section{PUBLISHER STATEMENT}

This work is made available according to the conditions of the Creative Commons Attribution-NonCommercialNoDerivatives 4.0 International (CC BY-NC-ND 4.0) licence. Full details of this licence are available at: https://creativecommons.org/licenses/by-nc-nd/4.0/

\section{LICENCE}

CC BY-NC-ND 4.0

\section{REPOSITORY RECORD}

Smith, Alister, Neil Dixon, Roger Moore, Philip Meldrum, Edward Haslam, and R. Siddle. 2019. "Performance of an Acoustic Emission Monitoring System to Detect Subsurface Ground Movement at Flat Cliffs, North Yorkshire, UK". figshare. https://hdl.handle.net/2134/16096. 


\title{
Performance of an acoustic emission monitoring system to detect subsurface ground movement at Flat Cliffs, North Yorkshire, UK
}

\author{
Dixon, N. ${ }^{1}$, Moore, R. $^{2}$, Spriggs, M. ${ }^{1}$, Smith, A. ${ }^{1}$, Meldrum, . $^{3}$, \& Siddle, ${ }^{4}{ }^{4}$ \\ ${ }^{1}$ Loughborough University, ${ }^{2}$ Halcrow-CH2M Hill, ${ }^{3}$ British Geological Survey, ${ }^{4}$ Scarborough \\ Borough Council
}

This paper describes the performance of an innovative acoustic emission subsurface slope displacement monitoring system installed in a large coastal landslide complex at Flat Cliffs, North Yorkshire, northeast England. Cliff instability is indicated by repeat deformation of an access road that serves a settlement of about 50 houses. As part of an extensive ground investigation, a sensor that can quantify acoustic emission was installed adjacent to a standard inclinometer, and continuous monitoring of acoustic emission has since taken place. The acoustic sensor has detected periods of slope deformation that are confirmed by manual surveys of the inclinometer. Performance is demonstrated using time series of acoustic measurements compared with ground deformations and triggering rainfall events.

Keywords: Acoustic Emission (AE), Landslide, Deformation, Instrumentation

\section{Introduction}

Instability of both natural and constructed slopes presently has a significant impact on the built environment and infrastructure in the UK with many tens of thousands of people living with slope instability. There is a need for cost-effective continuous real-time monitoring to inform risk assessments and provide early warning of instability. Such systems can play a key role in understanding the dynamic behaviour of hazards and the effective mitigation of risk by informing affected people and landowners. This paper describes an approach based on acoustic emission (AE) monitoring using Slope ALARMS sensors to assess displacement of a large coastal landslide, and compares performance with conventional inclinometer data.

\section{Acoustic Emission Monitoring of Soil Slopes}

Materials undergoing deformation generate acoustic stress waves (also known as acoustic emission (AE) and sub-audible noise). In soil, AE is generated from inter-particle friction and in rock by fracture propagation and displacement along discontinuities. AE monitoring is not a new technique and has been described in standard texts on geotechnical instrumentation (e.g. Dunnicliff 1988). A summary of international research to develop $\mathrm{AE}$ techniques for monitoring soil deformations is provided by Dixon et al. (2003). Dixon et al. (2003) and Dixon \& Spriggs (2007) report research to develop a method for quantifying detected AE to 
obtain displacement rates. This uses a standard waveguide assembly installed through existing or potential shear surfaces beneath the slope. Figure 1 shows a schematic of the measurement system using a standard and reproducible 'active' waveguide. Deformation of the soil body results in straining of the gravel that surrounds the steel tube, which emits high levels of $\mathrm{AE}$, and is then transmitted to ground level by the steel tube where a sensor detects and quantifies the AE activity. Field trials have demonstrated that slope deformations can be detected using this approach. Displacement rates are obtained by calculating AE count rates and the system is sensitive to changes in displacement rate, making the technique suitable for detection of changes in relative slope stability in response to destabilising (e.g. climate related) and stabilising (e.g. remediation) events.

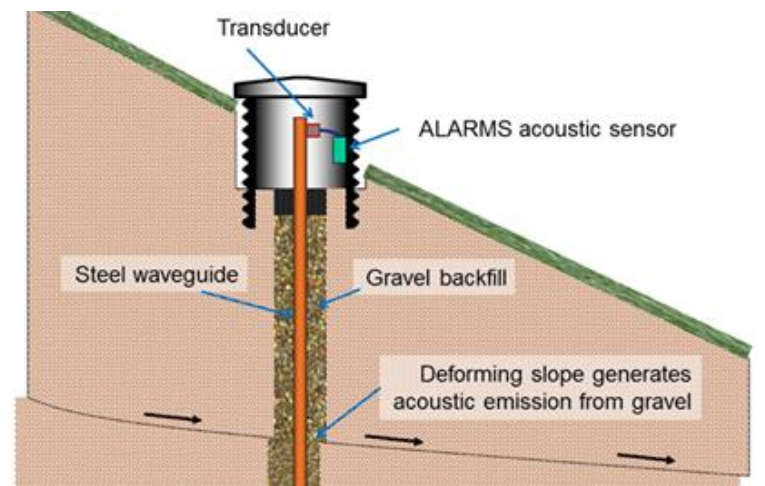

Fig. 1 Schematic of active waveguide installed through a slope after Dixon et al. (2012)

Historically, a key limitation on the use of the AE technique has been the cost and complexity of the monitoring instrumentation but this has now been solved by development of a unitary battery operated real-time acoustic emission slope displacement rate sensor called Slope ALARMS that was conceived by Dixon \& Spriggs (2011) and produced by the British Geological Survey in collaboration with Loughborough University. These sensors are being used in a number of proof-of concept trials (e.g. Dixon et al. 2010, Dixon et al. 2012). A key design aspect of the AE approach is the use of high monitoring frequencies (i.e. 20 to 30 $\mathrm{kHz}$ ). Filters are used to focus AE detection within this high frequency range to eliminate environmental noise such as generated by wind, traffic, humans and construction activities. The AE sensor is located on the active waveguide steel tube at ground level and protected by a cover. In real-time, generated AE are recorded at pre-defined time intervals. Measured AE rates are the number of times in each time period (i.e. 15, 30 or 60 minutes) that the detected signal exceeds a predetermined threshold (called ring down counts - RDC). RDC are used to derive displacement rates accurate to an order of magnitude, which is in line with current practice for classifying slope movements (i.e. slow, moderate, rapid). Recorded $\mathrm{AE}$ rates are compared to pre-determined trigger/action values. If a trigger value is exceeded, an alert message is sent to a nominated person for relevant action to be taken. 


\section{Flat Cliffs Field Trial of AE Sensor 3.1 Site description and instrumentation}

A large coastal landslide at Flat Cliffs, Filey, UK, was selected for comparison of AE monitoring, using the approach outlined in Section 2, with a manually read inclinometer (Figure 2). Periodic slope movements are triggered by excess rainfall and groundwater levels, and due to toe erosion by the sea. The geology at Flat Cliffs has been confirmed by ground investigations commissioned by Scarborough Borough Council in 2001 and 2011; the results have been interpreted by Halcrow. They established that all boreholes terminated within glacial sediments, at depths between 22.5 and $35.0 \mathrm{~m}$ below ground level (equivalent to $+13.09 \mathrm{~m}$ Ordnance Datum [OD] to $-12.36 \mathrm{mOD})$. Despite fragmentary core recovery, the data revealed that the site is underlain by glacial sediments comprising diamicts with localised and discontinuous stratified sands and gravel (meltwater deposits). The glacial sediments have a maximum recorded thickness of $35 \mathrm{~m}(-12.4 \mathrm{~m}$ OD), but could exceed this given that none of the boreholes encountered the underlying Kimmeridge Clay. The contact between the glacial sediment and Kimmeridge Clay at Flat Cliffs is therefore indicated to be an unknown depth beneath the base of the cliffs and beach. Due to the nature of the sediments and problems of core recovery, no pre-existing basal shear surfaces were logged in either ground investigation.

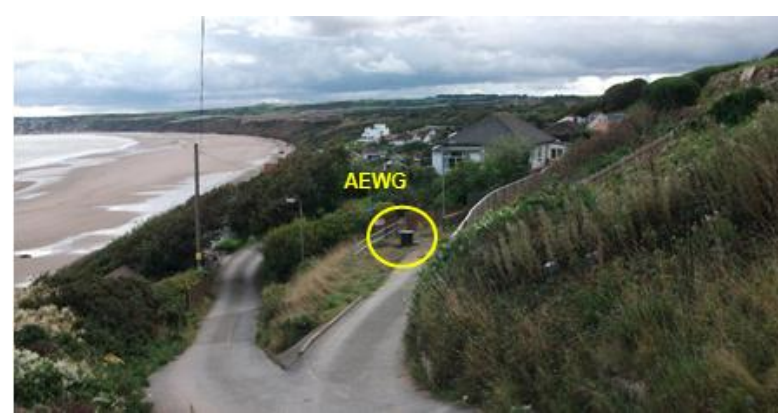

Fig. 2 Coastal cliff at Flat Cliffs and AE waveguide location

The waveguide was installed in a $130 \mathrm{~mm}$ diameter borehole to a depth of 25 metres below ground level, with the annulus around the steel tubing backfilled with compacted angular 5 to $10 \mathrm{~mm}$ gravel. The steel tube extends 0.3 metres above ground level and is encased in a secure protective chamber. A standard inclinometer casing was installed adjacent to the waveguide. The battery powered $\mathrm{AE}$ sensor is located inside the protective cover with the piezoelectric transducer coupled to the waveguide and monitoring is continuous with cumulative AE ring down counts recorded and time stamped for each monitoring period. Monitoring commenced at Flat Cliffs in September 2011 and has been continuous apart from short periods of down-time due to battery failure, with a monitoring interval of 30 minutes. Initially, the data was downloaded from the sensors manually during site visits to survey the inclinometer casing, however, more recently a wireless coordi- 
nator unit was installed which provided remote access to the sensors which allowed remote downloading of data and provided a facility for real-time communication of SMS messages when preset trigger thresholds were exceeded.

\subsection{Deformation history}

Ideally the continuous AE time history would be compared with a continuous time history of deformation measurements using an in-place inclinometer or ShapeAccelArray (SAA) but these were too expensive for use on this site. This high cost is a primary motivation for developing Slope ALARMS. Therefore, manual surveys of the inclinometer casing were conducted during site visits to provide subsurface deformation information. Negligible subsurface deformations were recorded from the start of monitoring in September 2011 until the start of 2013. This was anticipated due to the unusually dry weather in 2010/2011 combined with a relatively deep shear surface depth. High winter rainfall intensity and duration are required to increase groundwater (and therefore pore water pressure along the deep shear surface) to critical levels, reduce the shear strength and hence induce movement (e.g. Moore et al. 2010).

A prolonged period of above average precipitation occurred throughout the summer months of 2012 and this was followed by a wet winter in 2012/2013, and this rainfall pattern triggered deformations in early 2013. The inclinometer monitoring interval $17^{\text {th }}$ January $2013-22^{\text {nd }}$ March 2013 shows approximately $12 \mathrm{~mm}$ of resultant incremental shear surface displacements (dashed line in Figure 3) at 13.5 metres below ground level.

\subsection{Acoustic emission history}

Figure 3 shows AE rates (RDC per hour), rainfall per hour and cumulative inclinometer displacement (from a depth of 13.5 metres) for the period January to March 2013. Analysis of the AE time series is based on the premise that an increase in $\mathrm{AE}$ rate indicates a proportional increase in the rate of landslide displacement; a relationship described in Dixon \& Spriggs (2007). The AE time series can be used to produce continuous velocity-time profiles for landslide movements, and continuous cumulative displacements with high temporal resolution. The period of increased AE rates at the end of January 2013, which follows periods of intensive rainfall, is interpreted to define the initiation of landslide movement. The time-lag between the onset of movement and the significantly increased $\mathrm{AE}$ rates, and therefore increased velocity of movement, that occurred at the end of February and in the middle of March 2013 (peak of 3000+ RDC/hour) is hypothesized to be due to the low permeability characteristics of the landslide mass and the slow rate at which the antecedent rainfall events could infiltrate to the slip surface (this time lag could typically be 2-4 months; e.g. Fort et al. 2000 and Moore et al. 2010).

The AE rate vs. time curve shows surges of movement (Figure 3); such movement patterns cannot be detected using conventional inclinometers. The bell shaped (log-normal) curves are indicative of the landslide kinematics and are analogous to velocity profiles; the landslide velocity increases exponentially until 
a peak velocity is reached and the velocity subsequently decays exponentially. The fact that negligible AE was produced throughout the extended period of the slopes stability (September 2011 to early 2013) validates the assumption that these increased levels of $\mathrm{AE}$ produced during the period of landslide movement in early 2013, as evidenced from the inclinometer surveys, were induced by subsurface straining of the active waveguide in response to subsurface ground deformations.

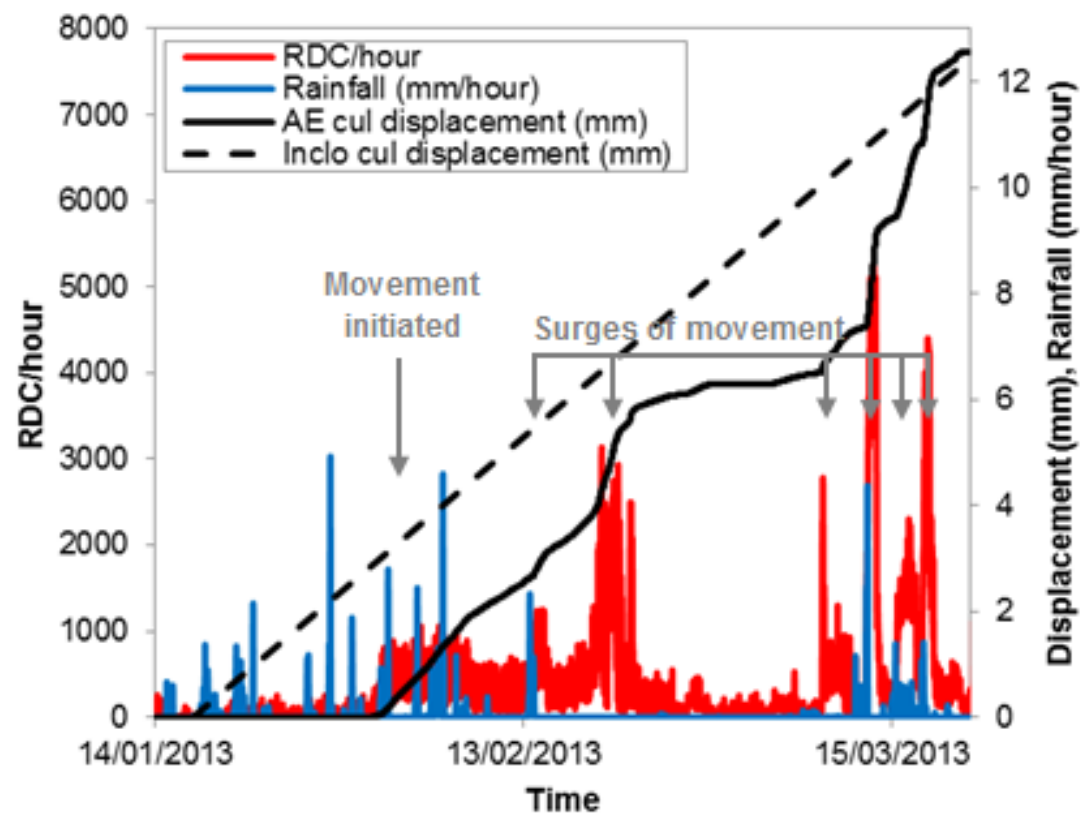

Fig. 3 RDC rate-, rainfall- and displacement- time behaviour for early 2013

\subsection{Deformation interpretation from $A E$}

The shape of the AE rate-time curves can be used to determine the velocitytime profiles for slope movement events by equating the area under the AE ratetime curve to the magnitude of shear surface displacement measured by the inclinometer for the period in which the events occurred. The area under the AE ratetime curve was determined using trapezoidal integration as the curves are formed of a series of data points which allows accurate interrogation using trapezoids. The total event displacement was distributed proportionately to each trapezoidal integrand and this allowed determination of the velocity over each trapezoid under the curve from the displacement/time relation. These velocity-time profiles were then utilized to determine the cumulative displacement profile throughout the inclinometer measurement interval to identify the timings and magnitudes of subsurface deformations with high temporal resolution (Figure 3). The total cumulative displacement for the period determined from $\mathrm{AE}$ data is assumed equal to the magnitude of displacement recorded by the inclinometer. This approach demon- 
strates the potential of continuous AE monitoring using technology such as Slope ALARMS sensors to deliver real-time deformation rate information.

\section{Summary}

The paper introduces the concept of using acoustic emission monitoring to assess stability of soil slopes and details operation of a unitary AE sensor that can be used to provide continuous real-time information on subsurface ground deformations. The AE sensor is being used to monitor landslide displacement at Flat Cliffs, Filey, North Yorkshire, UK, where performance is compared to standard inclinometer measurements. Results indicate that there is a direct relationship between $\mathrm{AE} \mathrm{RDC}$ and displacements, with increased $\mathrm{AE}$ rates following rainfall events indicative of slope displacements. Slope deformations occurred in early 2013 in response to consistently high precipitation in the summer of 2012 and winter 2012/2013. This period of deformation generated a characteristic bell shaped (log-normal) AE rate vs. time relationship indicating initial acceleration followed by deceleration of the slide body. The recorded AE rates have been used to derive cumulative displacements for the period of movement in early 2013. Field trials of the Slope ALARMS monitoring approach at Flat Cliffs and other sites are on-going and validation against continuous deformation data is expected in the near future.

\section{References}

Dixon, N. Hill, R. \& Kavanagh, J. 2003. Acoustic emission monitoring of slope instability: Development of an active wave guide system. Institution of Civil Engineers Geotechnical Engineering Journal, 156, 2, 83-95.

Dixon, N. \& Spriggs, M. 2007. Quantification of slope displacement rates using acoustic emission monitoring. Canadian Geotechnical Journal, 44, 6, 966-976.

Dixon, N., Spriggs, M.P., Meldrum, P., Ogilvy, R., Haslam, E. \& Chambers, J. 2010. Development of a low cost acoustic emission early warning system for slope instability. Proceedings $11^{\text {th }}$ International Association of Engineering Geologists, Editors Williams, A.L., Pinches, G.M., Chin, C.Y., McMorran, T.J. \& Massey, C.I. Taylor and Francis Pubs, Auckland, September, 1803-1810.

Dixon, N. \& Spriggs, M. 2011. Apparatus and method for monitoring soil slope displacement rate. UK Patent Application GB 2467419A, Awarded May 2011.

Dixon, N, M P Spriggs, P Meldrum, and E Haslam. 2012. "Field Trial of an Acoustic Emission Early Warning System for Slope Instability." In Landslides and Engineered Slopes: Protecting Society Through Improved Understanding, 1399-1404.

Dunnicliff, J. 1988. Geotechnical instrumentation for monitoring field performance, John Wiley \& Sons, pp 577.

Fort, D.S., Clark, A.R. and Cliffe, D.G. 2000. The Investigation and Monitoring of Coastal Landslides at Barton-on-Sea, Hampshire, UK. In: Bromhead, E.N., Dixon, N. \& Ibsen, M-L. (eds) Landslides in Research, Theory and Practice, Vol. 2, pp567-572. Thomas Telford, London.

Moore, R., Carey, J.M. and McInnes, R.G. 2010. Landslide behaviour and climate change: predictable consequences for the Ventnor Undercliff, Isle of Wight. Quarterly Journal of Engineering Geology and Hydrogeology, Vol. 43, pp447-460. 